\title{
Pesquisadores e legitimidade científica no campo da educação ${ }^{1}$
}

\author{
Célia Elizabete Caregnato \\ Denise Balarine Cavalheiro Leite \\ Bernardo Sfredo Miorando \\ Universidade Federal do Rio Grande do Sul (UFRGS)
}

Este artigo investiga como se constitui a legitimidade científica dos pesquisadores na área de educação no Brasil. A metodologia se compôs de estudos quantitativos sobre os currículos de pesquisadores de referência e de análise qualitativa de entrevistas. Os resultados mostram que, frente aos apelos à produtividade, os docentes organizam-se em redes de produção de conhecimento para além das redes de colaboração para coautorias. O estudo apresenta características do campo científico expressas na área da educação por meio de três casos representativos que mostram como o prestígio e a legitimidade nessa área podem ser alcançados por diferentes combinações de capital científico e político.

Palavras-chave: Pesquisadores. Campo científico. Educação. Legitimidade.

1 A pesquisa que serve de base para este artigo contou com o apoio do Conselho Nacional de Desenvolvimento Científico e Tecnológico (CNPq), Edital Ciências Humanas e Sociais nº 07/2011. Agradecemos o apoio, sem o qual não teria sido possível o desenvolvimento do estudo. Versão preliminar deste artigo foi apresentada à X Reunião da Associação de Pós-Graduação e Pesquisa em Educação (Anped) da Região Sul do Brasil em out./2014. 


\section{Researchers and scientific legitimacy in the field of education}

This article investigates how researchers build scientific legitimacy in the field of education in Brazil. The methodology involved quantitative studies on reference researchers' curricula and qualitative analysis of interviews. Results show that, in face of appeals for productivity, teachers organize themselves in networks of knowledge production that go beyond collaboration networks centered at coauthorships. The study presents characteristics of the scientific field represented in the area of Education through three expressive cases that show how prestige and legitimacy in this area can be achieved by different combinations of scientific capital and political capital.

Keywords: Researchers. Scientific field. Education. Legitimacy.

\section{Investigadores y legitimidad científica en el campo de la educación}

Este artículo investiga cómo se constituye la legitimidad científica de los investigadores del área de educación en Brasil. La metodología se compuso de estudios cuantitativos de los currículos de investigadores de referencia y de análisis cualitativa de entrevistas. Los resultados muestran que, frente alos llamados a la productividad, los docentes se organizan en redes de producción de conocimiento para allá de las redes de colaboración para coautorías. El estudio presenta características del campo científico expresas en el área de educacióna través de tres casos representativos que muestran como el prestigio y la legitimidad en esa área pueden ser alcanzados por diferentes combinaciones de capital científico y capital político.

Palabras clave: Investigadores. Campo científico. Educación. Legitimidad. 


\section{Introdução}

O campo acadêmico vem sofrendo profundas transformações que afetam os profissionais da área. O docente está submetido a exigências que dizem respeito ao aumento da produtividade individual, a avaliações e a prestações de contas (accountability), a critérios e exigências externas de qualidade, eficiência e eficácia aplicadas a seus fazeres acadêmicos. Tais acontecimentos que redesenham as universidades na contemporaneidade reproduzem práticas e lógicas típicas de mercados. No dizer de Ball, incidem sobre as subjetividades e performatividades individuais (BALL, 2010; 2012).

Especificamente no campo acadêmico da educação, possivelmente pelo fato de que pesquisam objetos mais diretamente imbricados com problemas humanos candentes do que outros campos homólogos, muitos pesquisadores têm dificuldade em aceitar tais lógicas. O campo da educação, como mostram Charlot (2006) e Laville e Dionne (1999), é multidisciplinar. Além disso, apresenta-se como um campo multiparadigmático. Por esses motivos, ele também é um campo epistemológico de fronteiras frágeis e pouco definidas.

Nesse campo, a produção do conhecimento não é uma tarefa somente técnica, pois, além de se constituir no âmbito de relações sociais e de poder (BOURDIEU, 2004), toma como objeto de estudo fenômenos atravessados por estas relações. Evidentemente, os processos de avaliação por pares e agências de fomento são respaldados por referenciais oficializados. Isso revela o esforço pelo uso de parâmetros comuns para ordenar classificações e rankings avaliativos, de maneira que se reconheça sua validade entre aqueles que compõem o campo e concorrem por reconhecimento. Essas forças e lógicas que avançam sobre o campo da educação avançam também sobre as subjetividades individuais, podendo dar ênfase ao produtivismo como valor e instituindo uma obsessão pela excelência (STOER; MAGALHÃES, 2005).

Entretanto, as relações e interações que permeiam o processo de produção acadêmica envolvem arranjos nem sempre explicitados. Aquilo que é publicado evidencia uma parte importante das atividades do pesquisador, do seu grupo e de sua rede; entretanto, não dá conta de mostrar o todo do seu trabalho. Parte substantiva dele diz respeito à sala de aula, à docência e ao seu envolvimento em outras atividades de importância para a profissão, em que se travam contatos com outros profissionais, formados ou em formação, em relações de parceria, orientação, ensino e aprendizagem. Ao se concentrar sobre critérios quantificáveis, a avaliação oficial tende a desvalorizar outros fatores de cunho qualitativo que constituem parte importante dos processos de trocas que ocorrem entre os pesquisadores.

Propusemo-nos, pois, a buscar elementos que, por não estarem valorizados nas práticas tradicionais, deixam de ser computados nas avaliações e acreditações 
reguladoras dos sistemas. Como reconhecido no Brasil (BIANCHETTI; MACHADO, 2009), as avaliações priorizam a produção acadêmica de pesquisadores, como é o caso da atribuição do status de pesquisador de excelência dos centros de pesquisa, do bolsista de produtividade em pesquisa 1A do Conselho Nacional de Desenvolvimento Científico e Tecnológico (CNPq) e da avaliação de programas de pós-graduação pela Coordenação de Aperfeiçoamento de Pessoal de Nível Superior (Capes).

Consideramos no estudo essas mesmas fontes oficiais e públicas, ou seja, a Plataforma Lattes e o Diretório de Grupos de Pesquisa (DGP) do CNPq. Porém, também procuramos ampliar a discussão com outros elementos que expõem formas de trabalhar em rede de pesquisa e que expressam outros lugares que os pesquisadores ocupam. Perguntamos como ocorre a interação que propicia a legitimação do conhecimento produzido por pesquisadores com destaque em sua área de atuação - a educação. Especificamente, tratamos de entender que mecanismos de cunho institucional/estrutural contribuem para formar e organizar redes de colaboração científica e grupos de pesquisa. Como incidem as relações de poder e hierarquias? O que as redes de pesquisa revelam sobre as relações de caracteres macro e microssociológico que permeiam a produção e a organização do conhecimento acadêmico-científico? Que aspectos contribuem para obter e manter a legitimidade dos grupos organizados em redes? Buscamos, a partir de sujeitos específicos, entender como o conhecimento acadêmico se organiza. Para tanto, analisamos elementos particulares que se destacam na articulação entre indivíduos e grupos nos espaços da educação superior.

Neste artigo, descrevemos as etapas da metodologia, os entendimentos sobre ciência, produção de conhecimento e campo científico da educação com apoio principalmente em Stephen Ball e Pierre Bourdieu. Apresentamos a análise dos dados relativos aos currículos dos sujeitos pesquisados e discutimos as falas dos pesquisadores entrevistados, bem como consideramos especificamente três deles como casos paradigmáticos, isto é, casos que inspiram pensar aspectos da atividade acadêmica na área/campo da educação. Ao concluir, questionamos as transformações e pressões pelas quais passa a educação superior e as modificações aos modos de organizar e produzir conhecimentos em educação que elas impõem. 


\section{Metodologia}

O objeto de pesquisa constitui-se no grupo de pesquisadores de excelência da área da educação no Brasil. A metodologia abrangeu estudos quantitativos sobre os currículos destes pesquisadores e estudos qualitativos sobre material de entrevistas. Para a escolha dos sujeitos, adotamos como critérios a posição do pesquisador no topo da carreira, ou seja, como bolsista de produtividade em pesquisa do CNPq, e sua liderança expressa em uma rede de colaboradores que se manifesta no registro, no DGP/CNPq, de um grupo de pesquisa formado há, pelo menos, dez anos (LEITE; LIMA, 2012). Na coleta de dados, conduzida no ano de 2011, identificamos dez sujeitos que se adequaram aos critérios.

Em uma primeira etapa do trabalho do nosso grupo de pesquisa, quando se considerou prioritariamente a produção registrada nos Currículos Lattes, analisamos as produções em artigos, livros e capítulos de livros, e esse material formou o corpus principal de dados para a primeira fase de análise. Nessa etapa, compilamos as informações referentes às publicações e aos coautores envolvidos no período. Com o recurso dos softwares Bibexcel e Pajek, mapeamos as redes de pesquisa na forma de grafos, dando origem a representações de teias do conhecimento (MIORANDO; LEITE, 2012).

Em um segundo momento, entrevistamos pesquisadores e, a partir de suas falas, procuramos entender o modo como viabilizam e interpretam suas redes de pesquisa. Por meio das entrevistas, os informantes falaram de suas experiências e percepções sobre as atividades que desenvolvem em rede. As entrevistas foram analisadas com base em categorias que permitiram o estabelecimento de relações entre si e com os elementos que formam o contexto do problema (FLICK, 2009). A análise desses dados apoiou-se também nas obras de Grawitz (1986), Laville e Dionne (1999) e Ludke e André (2008).

Paralelamente, na constituição do corpus da pesquisa, reunimos dados sobre a trajetória dos pesquisadores, empreendendo uma busca mais ampla nas informações disponíveis no banco de dados Lattes do CNPq. Localizamos formação acadêmica, funções, postos e atividades assumidas pelos pesquisadores e atividades de gestão acadêmica ou funções de caráter mais claramente político que foram ocupadas. O material permitiu conhecer elementos do trabalho individual e em redes, bem como os processos de ação científica e política e de produção do conhecimento privilegiados pelos sujeitos.

Com a análise do conjunto disponível de dados, formulamos hipóteses sobre o que estrutura e mantém a condição de líder prestigiado no campo da educação. Especificamente, consideramos três entre os sujeitos investigados como casos paradigmáticos, isto é, casos que inspiram pensar aspectos da atividade acadêmica 
na área/campo da educação. Essas informações estabelecem inferências que descrevemos neste artigo.

\section{Ciência, produção do conhecimento e campo científico}

A produção do conhecimento nas ciências e a sua organização no meio acadêmico ocorrem com base em processos que são sociais, e isso significa que neles incidem relações complexas e, em especial, relações de poderes. Os arranjos para esta produção apresentam particularidades conforme as áreas específicas em que se dão e se modificam por meio da história. Por conta disso, também não é unívoca a ideia de como se produz o conhecimento científico. Nesse estudo, colocamos atenção na área de educação e em suas formas de "fazer ciência".

Merton (1985) concebe a ciência como formada por uma comunidade científica, um lugar especial em que a atividade seria movida por uma moral colaborativa e por um desinteresse em outras questões para além da própria busca pelo conhecimento. Esta ideia foi posta em questão por diversos estudiosos. As questões levantadas colaboram para uma aproximação com a realidade atual da pesquisa científica e sua repercussão em instituições de pesquisa e ensino como o são as universidades.

Gibbons et al. (1997), por exemplo, trataram de dois modos de produzir ciência, permitindo ver que havia mudanças na forma de produzir conhecimento e de entrelaçar atores e instituições. Em um novo modo de ciência, distinto do mertoniano, destacam-se a interdisciplinaridade, a maior aproximação entre universidades e empresas para efetivação de um conhecimento aplicável, a inovação tecnológica e sua difusão na sociedade. Trata-se da lógica de produção presente na sociedade capitalista em sua fase avançada, em que a mercadoria comercializável torna-se mais fortemente o centro da organização, não só econômica, mas também social. Nesse contexto, ocorrem reconfigurações institucionais, modificações na aplicabilidade e no acesso ao conhecimento e inclusive na amplitude e nos formatos de escolarização. As redes de produção de conhecimento, nas várias áreas científicoacadêmicas, contam mais claramente com colaboração e competitividade nos níveis micro e macrossocial.

Santiago, Carvalho e Ferreira (2013), por meio de um estudo empírico sobre narrativas em websites de universidades públicas portuguesas, mostram que há convivência entre diferentes maneiras de anunciar os modos de produção de conhecimento, as quais evidenciam ações e intencionalidades institucionais. Nestas universidades, convivem afirmações de base mertoniana, sinalizando valorização de pilares tradicionais na produção da ciência - desinteresse, originalidade, universalismos, comunitarismo e ceticismo - com anúncios de um modo no qual 
critérios exógenos ganham crescente importância na formulação da agenda de investigação. O fenômeno pode ser visto, por exemplo, por meio da valorização: a) da pesquisa aplicada; b) da interdisciplinaridade como estratégia pragmática frente a razões epistemológicas; c) da interação com agências governamentais, indústria e serviços com vistas à obtenção de financiamentos; d) de foco no prestígio externo que produz linha tênue entre relativa autonomia na produção de conhecimento e atendimento a pressões de mercado para gerar inovação tecnológica.

Essa realidade das universidades públicas portuguesas é convergente com aspectos observados também nas universidades brasileiras (LEITE, 2011; LEITE; GENRO, 2012), e isso explicita que, em países e universidades com histórias bastante distintas entre si, há tendências comuns no modo de fazer e/ou de anunciar a pesquisa acadêmica. De outra parte, o recorte de análise que fazemos nos leva a considerar que há variações sobre os modos de produzir ciência e de disponibilizar seus resultados, de acordo com as especificidades dos subcampos científicos.

Analisando o trabalho acadêmico e a produção do conhecimento com foco especial na área de educação, Stephen Ball (2010; 2012) trabalha a noção de performatividade como cultura que regula os indivíduos no campo da educação, a partir de referenciais de produção para o mercado. A performatividade situa-se no trabalho das pessoas e mostra relações de poder incorporadas ao cotidiano da educação. Assim ocorre a constituição de subjetividades que adotam autocontrole capaz de produzir resultados continuamente avaliados. Qualidade, eficiência e prestação de contas são termos-chave do discurso performático e do poder que cria verdades, rotinas e muda identidades. Então, a submissão a avaliações e à prestação de contas, relações típicas de mercado, passam a dominar a atividade profissional e, para isso, criam-se formatos para apresentação de desempenho a serem avaliados, tendo em vista que esses personagens precisam apresentar-se para prestar contas (accountability).

Para Ball (2010), os indivíduos e as organizações são vistos por meio de seu desempenho no sistema, de sua produtividade e dos resultados que produzem. Neste mesmo sentido, Leite e Lima (2012) reúnem colaborações de diversos autores que lidam com o tema das redes de pesquisa e da lógica de produção na qual o trabalho acadêmico está envolto, mostrando traços dessa realidade em casos analisados. As autoras exploram e criticam a penetração da lógica produtivista no meio acadêmico e sua interferência na formação de pessoas e nos modos de produção do conhecimento.

De outra parte, Machado e Bianchetti (2011) mostram como as agências de fomento, gestão e avaliação da pós-graduação no Brasil transformaram-se em meios de regulação da produção, de maneira a atingir diretamente o cotidiano de trabalho dos pesquisadores e docentes nas universidades brasileiras. Eles tomam por base elementos históricos e teóricos que destacam a lógica da produção de riqueza 
por meio da ação de mercados, governos e órgãos que se atualizam na presente fase da produção capitalista e discutem as mudanças na universidade brasileira com a sobrecarga de trabalho e a falta de autonomia, as quais os intelectuais e pesquisadores estão submetidos. $O$ argumento central é de que a autonomia precisa ser afirmada e está ligada ao esforço desses sujeitos em ação.

Por sua vez, a abordagem da sociologia da ciência de Pierre Bourdieu nos oferece aporte teórico-metodológico neste estudo. Para analisar as operações básicas da ciência, é necessário apreendê-la por meio de seu universo de funcionamento, ou seja, do campo científico. Segundo Bourdieu (1983), esse é um campo social como qualquer outro, permeado por lutas concorrenciais, relações de força, monopólios, estratégias, interesses e lucros. Nesse campo, o que está em jogo é o monopólio da competência científica, ou seja, a capacidade de agir e falar legitimamente.

Bourdieu, em um contraponto à ideia de comunidade científica, expõe que as forças no interior de um campo estão distribuídas desigualmente. De um lado, há posições mais altas na detenção do capital científico; de outro, estão os novatos, que possuem condição variável de acordo com a importância dos recursos científicos que detêm. O que o sociólogo procura demonstrar é que os agentes que estão inseridos no campo científico operam com interesse. Afirma que aquilo que é percebido como importante e interessante pelos agentes é "aquilo que tem a possibilidade de fazer aparecer aquele que o produz como importante e interessante aos olhos dos outros" (BOURDIEU, 1983, p. 125). A explicação bourdieusiana para concentração dos pesquisadores em torno de objetos considerados mais importantes socialmente é feita assinalando a acumulação de prestígio simbólico: "[...] a tendência dos pesquisadores a se concentrar nos problemas considerados como mais importantes se explica pelo fato de que uma contribuição ou descoberta a essas questões traz um lucro simbólico mais importante" (op. cit.).

O campo científico está estruturado por meio da distribuição desigual de dois tipos de capital científico: o puro e o político (BOURDIEU, 2004). O primeiro é ligado ao reconhecimento do pesquisador junto aos pares-concorrentes do campo, e o segundo é vinculado à inserção dos pesquisadores em posições importantes e em cargos de gerência nas instituições científicas. Essas duas formas de interpretar o lugar ocupado pelos agentes no campo é produtiva e nos permite ver que estes dois tipos de capital por vezes andam juntos, mas isso não ocorre necessariamente. Buscamos elementos nos dados empíricos que nos permitiram visualizar a presença destes tipos de capital entre os pesquisadores que investigamos. 


\section{Educação como campo acadêmico de pesquisa}

O campo acadêmico da pesquisa em educação, conforme as contribuições teóricas de Bernard Charlot (2006) e Bernardete Gatti (2001), tem três características fundamentais. Primeiro, trata-se de uma área do saber marcada por uma dimensão teórica de caráter multidisciplinar. Essa formação tradicionalmente ocorre com contribuições da Sociologia, da Antropologia, da Psicologia e da Filosofia. Seu substrato teórico é multiparadigmático e isso o define como um campo epistemologicamente menos delimitado ou frágil (CHARLOT, 2006). Segundo, o campo da educação apresenta uma dimensão social com práticas e políticas educacionais de urgência, com necessidades prementes no tratamento e na produção de respostas aos problemas. Por fim, sua metodologia é marcada fortemente pela fusão da pesquisa e da ação, formando o que Gatti (2001) chama de "pesquisa-ação". Neste campo, a necessidade de interpretar ou teorizar está mais fortemente vinculada ao objetivo de planejar e produzir políticas para a intervenção ou a ação, as quais efetivam as práticas educativas.

A interpretação da organização acadêmico-científica do conhecimento requer trabalhar com sua lógica de desenvolvimento ampla, mas também com as peculiaridades internas de cada campo. Pierre Bourdieu (2004) mostra, em "Os usos sociais da ciência", que a constituição de um (sub)campo científico, além de ter objeto específico, localiza-se em um universo mais extenso do que ele próprio. No campo, há espaço de interação entre agentes e instituições, os quais passam a constituir, entre si, certo nível de vida própria. O campo científico e cada um dos subcampos - assim entendidos os aparatos em torno dos quais se organizam as áreas de conhecimento - formam espaços com regras coerentes ao campo, mas também com relativa diferenciação na atuação. Diante disso, indagamos sobre a possibilidade de verificação de especificidades empíricas do subcampo da educação. Cabe salientar que entendemos a área acadêmica de pesquisa em educação como um subcampo, no interior do campo científico. Apesar disso, utilizamos a noção de campo para discutila, uma vez que, sendo parte, também possui elementos que a caracterizam como uma totalidade.

Elegemos três elementos-chave para interpretar a produção do conhecimento e do prestígio entre líderes de grupos de pesquisa na área da educação: a formação; as características da produção; e a atuação na vida acadêmica. Além disso, buscamos a ótica dos pesquisadores sobre fatores que se relacionam de maneira relevante à sua atividade de pesquisa.

A tabela 1 foi elaborada a partir dos itens valorizados no Currículo Lattes para fins de avaliação da produção do pesquisador brasileiro pelos órgãos oficiais. Embora ainda não apareçam elementos como orientações de alunos, a produção por meio de publicações constitui-se em referencial forte. No caso dos dez líderes no DGP/CNPq, 
vemos números esclarecedores. Constatamos, por exemplo, que há importantes diferenças quantitativas quanto às publicações registradas pelos pesquisadores.

\section{TABELA 1}

PUBLICAÇÕES EM ARTIGOS, CAPÍTULOS DE LIVROS E LIVROS NO PERÍODO 2001-2010 POR PESQUISADORES EM EDUCAÇÃO (PE)

\begin{tabular}{|c|l|l|l|}
\hline PE & Publicações & PE & Publicações \\
\hline PE1 & 84 & PE6 & 32 \\
\hline PE2 & 46 & PE7 & 62 \\
\hline PE3 & 27 & PE8 & 53 \\
\hline PE4 & 71 & PE9 & 50 \\
\hline PE5 & 47 & PE10 & 49 \\
\hline
\end{tabular}

Elaboração própria, com base em CNPq (2011).

A diferença entre aquele que mais produziu e o que menos publicou é de 84 para 27 produtos e isso mostra uma variação expressiva. Embora a maioria dos pesquisadores esteja entre 50 e 60 produtos, esses dados nos levam a considerar que, para além da questão numérica das publicações, outros fatores interferem na classificação do líder de pesquisa no topo do ranking.

Quando se observa essa produção em detalhes (tabela 2), encontramos algumas regularidades. Quanto à produção bibliográfica, é possível afirmar que o meio de divulgação preponderante entre os pesquisadores é o de capítulos de livros. Esses são seguidos por artigos, que são mais frequentes do que livros, como obras integrais ou como coletâneas. Apenas dois pesquisadores têm maior número de artigos do que de capítulos de livros.

\section{TABELA 2}

PRODUÇÃO DETALHADA NO PERÍODO 2001-2010 POR PESQUISADOR EM EDUCAÇÃO (PE)

\begin{tabular}{|l|l|l|l|l|l|}
\hline \multirow{2}{*}{ PE } & \multicolumn{5}{|l|}{ Tipo de produção } \\
\cline { 2 - 6 } & $\begin{array}{l}\text { Dissertações } \\
\text { orientadas }\end{array}$ & $\begin{array}{l}\text { Teses } \\
\text { orientadas }\end{array}$ & $\begin{array}{l}\text { Capítulos de } \\
\text { livros }\end{array}$ & $\begin{array}{l}\text { Artigos em } \\
\text { periódicos }\end{array}$ & $\begin{array}{l}\text { Livros } \\
\text { publicados }\end{array}$ \\
\hline PE1 & 15 & 10 & 51 & 23 & 10 \\
\hline PE2 & 9 & 8 & 27 & 15 & 4 \\
\hline PE3 & 7 & 11 & 5 & 20 & 2 \\
\hline PE4 & 17 & 5 & 45 & 25 & 1 \\
\hline PE5 & 14 & 14 & 7 & 40 & 0 \\
\hline
\end{tabular}




\begin{tabular}{|l|l|l|l|l|l|}
\hline PE6 & 11 & 11 & 21 & 11 & 0 \\
\hline PE7 & 9 & 14 & 33 & 26 & 3 \\
\hline PE8 & 13 & 7 & 25 & 25 & 3 \\
\hline PE9 & 1 & 12 & 30 & 11 & 9 \\
\hline PE10 & 16 & 9 & 31 & 18 & 0 \\
\hline Total & 112 & 101 & 275 & 214 & 32 \\
\hline Média & 11,2 & 10,1 & 27,5 & 21,4 & 3,2 \\
\hline
\end{tabular}

Elaboração própria, com base em CNPq (2011).

conjunto de elementos mostra convergência com o fato de que, em um contexto de imediatismo na produção, as publicações que demandam maior reflexão e tempo, como é o caso dos livros, acabam perdendo prestígio. Da mesma maneira, os números de capítulos de livros e artigos superam o de dissertações de mestrado e teses de doutorado orientadas, trabalhos que exigem longa maturação. De qualquer forma, os periódicos avaliados por pares tornam-se crescentemente um recurso importante para fins de divulgação da produção porque também são contabilizados em rankings de prestígio, por meio de uma classificação oficial do órgão avaliador Capes, denominada Qualis. Esses fenômenos são marcantes em anos mais recentes, quando rankings passaram a ser mais intensamente disputados e integrados à lógica do campo científico.

De outra parte, a identificação de elementos sobre trajetória acadêmica dos agentes também permite considerar outras características da produção bibliográfica do campo da educação. Ela é um dos componentes de formação e constituição daquilo que Bourdieu (1989) denomina de habitus, ou seja, um conjunto de disposições incorporadas ao longo da experiência social dos agentes.

De modo geral, as publicações em coautoria internacional ou em veículos de outros países realizadas pelos cinco pesquisadores com maior produção bibliográfica entre os dez sujeitos de pesquisa estão restritas a duas universidades portuguesas: Universidade Católica do Porto e Universidade do Minho. Esse escopo converge dois fatores apontados por Fiorin (2007) para explicar a baixa internacionalização da publicação científica nas áreas de Ciências Humanas e Sociais (CHS):

a) a cultura de publicação, em que se destaca, em primeiro lugar, a preferência por formatos editoriais distintos das publicações periódicas ou em série; em segundo, a impossibilidade ou dificuldade de pôr o nome em trabalhos de orientandos ou de colegas; b) a natureza do objeto de estudo construído pelas $\mathrm{CHS}$, que limita e circunscreve a dimensão externa do respectivo impacto, uma vez que o fato de tratar de temas relativos às realidades mais "locais", de âmbito definido por fatores espaço-temporais específicos, justifica o reduzido interesse e o pouco empenho de sua difusão em escala internacional (FIORIN, 2007, p. 272). 
De fato, não há um conjunto numérico expressivo de produções bibliográficas em coautoria com/no exterior. Isso não é novidade e indica uma das marcas das publicações dos pesquisadores brasileiros nas áreas de CHS. Não há destaque quanto a publicações no exterior, embora possa existir certo nível de intercâmbio, trocas e outros tipos de produções.

Ainda, levamos em consideração outros aspectos. Entre eles, destacamos a formação no nível de doutorado, conforme o quadro 1.

\section{QUADRO 1}

PERÍODO E LOCAL DE DOUTORADO POR PESQUISADORES EM EDUCAÇÃO (PE)

\begin{tabular}{|l|l|l|}
\hline \multirow{2}{*}{ Pesquisador } & Doutorado & Local \\
\cline { 2 - 3 } & Década & França \\
\hline PE1 & 1970 & Brasil \\
\hline PE2 & 1980 & Brasil \\
\hline PE3 & 1990 & Inglaterra \\
\hline PE4 & 1980 & Brasil \\
\hline PE5 & 1970 & Inglaterra \\
\hline PE6 & 1980 & Brasil \\
\hline PE7 & 1980 & França \\
\hline PE8 & 1960 & Brasil \\
\hline PE9 & 1970 & Espanha \\
\hline PE10 & 1960 & \\
\hline
\end{tabular}

Elaboração própria, com base em CNPq (2011).

Buscamos tendências a partir dos períodos de realização de doutorados e dos locais de formação. Vemos que cinco dos dez pesquisadores identificados na coleta de 2011 realizaram seus doutorados no Brasil. Podemos ver uma amostra heterogênea em termos de lugar de formação, em que as influências internacionais igualar-seiam às nacionais. Quanto aos períodos, observamos distribuição entre as décadas de 1960 e 1990, quando se constitui a pós-graduação no Brasil, sob a orientação da Capes. Esses pesquisadores contribuíram para a consolidação da pesquisa e pósgraduação no Brasil.

É relevante ver que os pesquisadores apresentam trajetórias bastante distintas quanto à atuação em cargos acadêmicos de gestão da pesquisa e na ocupação de lugares políticos de destaque, de acordo com a tabela 3 . 
TABELA 3

CARGOS OU FUNÇÕES, EM NÚMERO DE ANOS, POR PESQUISADORES EM EDUCAÇÃO (PE)

\begin{tabular}{|c|c|c|c|c|c|}
\hline \multirow[b]{2}{*}{ PE } & \multicolumn{5}{|c|}{ Cargo ou função } \\
\hline & $\begin{array}{l}\text { Presidente } \\
\text { ou vice de } \\
\text { associação } \\
\text { nacional }\end{array}$ & $\begin{array}{l}\text { Coordenador } \\
\text { de Programa de } \\
\text { Pós-Graduação }\end{array}$ & $\begin{array}{l}\text { Diretor } \\
\text { ou vice de } \\
\text { faculdade }\end{array}$ & $\begin{array}{l}\text { Chefe ou } \\
\text { vice de } \\
\text { departamento }\end{array}$ & $\begin{array}{l}\text { Membro de } \\
\text { comissão } \\
\text { em órgão de } \\
\text { fomento* }\end{array}$ \\
\hline PE1 & 5 & 2 & - & 1 & - \\
\hline PE2 & 4 & - & 4 & 6 & 11 \\
\hline PE3 & - & - & - & 3 & - \\
\hline PE4 & 6 & 8 & - & - & - \\
\hline PE5 & - & - & - & - & 41 \\
\hline PE6 & - & - & - & - & - \\
\hline PE7 & - & 3 & - & - & - \\
\hline PE8 & - & - & - & 3 & 4 \\
\hline PE9 & - & - & 4 & - & - \\
\hline PE10 & - & - & - & - & 2 \\
\hline
\end{tabular}

Elaboração própria com base em CNPq (2011).

Nota: * Somando tempo de atuação em órgãos federal e estaduais.

\section{Educação como campo científico-acadêmico amplo}

Para avançar na compreensão dos processos de produção de conhecimento da área da educação, é preciso articular o conceito de habitus aos de campo e capital. É a partir deles que podemos conceber teoricamente tal área como um espaço social de lutas, em que o que está em jogo é "o monopólio da produção cultural legítima" (CATANI, 2011, p. 194).

Além dessas propriedades gerais de todos os sistemas que constituem uma sociedade, Bourdieu (2004) também observa outra propriedade fundamental dos campos: o conceito de capital. É com base nele que o autor explica a organização da estrutura de diferentes campos. Cada um deles é o lócus da constituição de uma forma específica de capital. No caso do campo científico, o que define sua estrutura é a distribuição desigual de capital científico entre os seus diferentes agentes.

Bourdieu destaca que o capital científico pode se manifestar sob duas formas. Por um lado, podemos falar em capital científico puro: fundamentalmente, trata-se do reconhecimento junto aos pares-concorrentes do campo em questão. Por outro, podemos falar em capital científico temporal ou político, pensando nas posições de prestígio dentro de instituições científicas. $O$ autor detalha da seguinte maneira as diferentes formas de acumulação de capital científico: 
as duas espécies de capital científico têm leis de acumulação diferentes: o capital científico "puro" adquire-se, principalmente, pelas contribuições reconhecidas ao progresso da ciência, as invenções ou as descobertas (as publicações, especialmente nos organismos mais seletivos e mais prestigiosos, portanto aptos a conferir prestígio à moda de bancos de crédito simbólico, são o melhor indício); o capital cientifico da instituição se adquire, essencialmente, por estratégias políticas (específicas) que têm em comum o fato de todas exigirem tempo - participação em comissões, bancas (de teses, de concursos), colóquios mais ou menos convencionais no plano científico, cerimônias, reuniões etc. [...] (BOURDIEU, 2004, p. 36).

Ao construir esse arcabouço teórico, Bourdieu consegue efetivamente superar a clássica dicotomia entre correntes das Ciências Sociais e apreender aspectos da realidade social sob duas dimensões. Uma delas é classificada como objetivista e compreende a estrutura lógica de organizações sociais, levando-se em conta seu conjunto de normas, regras e instituições. A outra dimensão, classificada como subjetivista, compreende a relação de forças simbólicas que condicionam diferentes formas de percepção e apreciação dos agentes sociais.

Ao falarmos de habitus científico, no entanto, parece ser mais adequado nos referirmos a estratégias do que a regras, tendo em vista o caráter de síntese da teoria de Bourdieu. Ou seja, mais do que apenas reprodutores de normas institucionalmente estabelecidas, é importante destacar o senso prático que os agentes possuem, as estratégias que adquirem pela experiência no campo. A noção de estratégia não pode ser confundida com um cálculo consciente e racional, mas deve ser entendida como um domínio prático da lógica de determinado campo. Nos casos investigados, vemos algumas estratégias que valorizam mais fortemente a intervenção política e social relacionada ao meio profissional e reconhecemos outras que investem mais intensamente na ação concentrada no ambiente de formação acadêmica e produção científica, na universidade.

As entrevistas permitem ver que nem sempre a troca intelectual entre os pesquisadores é materializada na forma de publicações clássicas, em artigos, capítulos de livros ou livros. Um dos entrevistados relata o seguinte: "[...] isso que eu acho importante, porque eu acho que a Plataforma [Lattes] dá muita pouca notícia da dinâmica, ela é muito enrijecida, [...] porque ela não dá ideia do que são os vínculos, do que são as redes" (PE1). E, em um raciocínio convergente, expõe: "para mim, a rede não é apenas o resultado das publicações, mas a soma dos nossos trabalhos conjuntos" (PE1).

Para esses pesquisadores, não obstante haja relação entre as duas noções, a colaboração científica não se restringe à coautoria. Ela é traduzida pela ideia de que ocorrem trocas e trabalhos em conjunto. No entanto, essas atividades não necessariamente são registradas em produções bibliográficas. A coautoria consiste na materialização, na forma de publicação, dos trabalhos realizados em conjunto. Assim, a colaboração científica realizada entre os acadêmicos perpassa e extrapola 
os dados registrados na Plataforma Lattes, formando intercâmbios intelectuais que muitas vezes não estão explicitados nos dados apropriados nesses registros.

O pesquisador PE1 possui a maior quantidade de produção bibliográfica do grupo pesquisado e significativa inserção política, sendo que sua produção é marcada por certo pragmatismo no campo da pesquisa, atuando junto a professores das escolas, por exemplo, e buscando formar professores associados em rede.

Eu trabalho com professor desde sempre, porque a minha preocupação é exatamente mostrar que o professor não se forma num curso, ele se forma em rede. Então, como é que são essas redes, como é que essas redes funcionam? Então, estou trabalhando agora com o que chamo de mundo cultural do professor (PE1).

Com uma leitura mais detalhada dos depoimentos dos entrevistados, percebemos a necessidade de ampliarmos o conjunto de variáveis relevantes para compreendermos o campo científico da educação. Além de variáveis como formação acadêmica, produção bibliográfica, poder político (ou "capital científico político", de acordo com a terminologia de Bourdieu), é necessário também levarmos em consideração a forma como foi constituída a carreira acadêmica dos pesquisadores, ou seja, a experiência deles. Neste sentido, o relato do pesquisador PE3 é relevante:

mas vocês poderiam me perguntar: "mas por que não tem rede?". Eu tenho muito trabalho aqui e de certa maneira eu sou na área um ponto fora da curva. O que eu quero dizer com isso: eu não faço aquele tipo de coisa de fazer política acadêmica. Eu sou meio arredia a isso e talvez porque eu esteja já há muito tempo, quase todo mundo eu conheço de vista, me conhecem de vista e eu não faço aquele jogo de elogio fácil e sou muito crítica. Então, o que acontece, não faço uma coisa que é própria do campo acadêmico [...]: "me cita que eu te cito". Não vou citar fulano porque está fazendo a mesma coisa que eu. Não quero aquela competição que é própria a toda área, mas eu [...] consegui uma posição no campo muito antes dessas coisas. Uma posição de campo que eu até diria para vocês, foi muito fácil, porque naquela época não se fazia pesquisa na área da educação (PE3).

O depoimento acima contribui para compreender como vinha sendo viabilizado o prestígio dentro do campo da educação em tempo anterior às transformações do ensino superior, que passaram a exigir do pesquisador mais do que "naturalmente" dar aulas e fazer pesquisa. Nesse cenário, o valor do pesquisador começa a ser definido por outros fatores, que passam pela produtividade visibilizada em artigos aceitos e veiculados em journals de prestígio internacional indexados nas grandes bases de dados, classificados com alto fator de impacto e reputados nos altos estratos do Qualis, entre outras medidas de distinção. Esse é um fenômeno próprio do campo científico como um todo, não obstante o campo da educação apresentar um modus operandi que difere de outras ciências.

Quanto à estratégia de conquista do prestígio por parte dos pesquisadores $1 \mathrm{~A}$ 
em educação, as entrevistas não põem relevo à utilização de mecanismos como ocupação de cargos administrativos dentro de instituições científicas e de fomento, alta produção bibliográfica e política acadêmica do "jogo de citar e ser citado". De fato, no caso de PE3, podemos afirmar, com base em sua produção e em seu discurso, que seu prestígio foi viabilizado em grande parte por meio da experiência que teve origem em um período inicial das atividades de pesquisa e pós-graduação institucionalizadas na academia brasileira, em fins dos anos 1960.

O pesquisador em questão demonstra uma singularidade: consolidou sua carreira acadêmica em um período histórico em que as exigências formais eram notavelmente diferentes do presente e o nível de concorrência no campo era significativamente mais baixo. A afirmação a respeito da sua trajetória na pós-graduação ilustra bem esse panorama: "então eu diria que a minha história de pesquisadora é paralela à pós-graduação e depois na pós-graduação" (PE3). Vemos que PE3 indica a presença da pesquisa no início e ao longo da sua trajetória acadêmica, até mesmo antes de sua titulação doutoral, obtida na década de 1990. Outro aspecto a salientar, neste caso, é o fato de que, em um segundo momento, acentua-se a sua atividade de pesquisa na condição de docente na pós-graduação.

Já o pesquisador PE2 tem importante inserção, como se pode verificar na tabela 3. É notável sua rede de contatos internacionais que, apesar de não estar materializada em publicações, contribui para o intercâmbio do conhecimento, como se vê na afirmação que segue:

sou muito mais aquilo que para mim é fundamental, que é o intercâmbio na produção do conhecimento [...]. eu acho que essa produção conjunta é positiva, porque você cria um diálogo [...]. Eu trouxe o [nome removido para evitar identificação do sujeito] duas vezes ao Brasil, ele deu um curso, deixou todos os projetos dele [...], mas você vai só entender isso se você entrar nos auxílios à pesquisa que eu solicitei, que foi um para [fundação estadual de amparo à pesquisa] e outro ao CNPq, mas isso não está no Lattes (PE2).

Nesse caso, a pesquisadora salienta que suas atividades, mesmo com conexões e parcerias internacionais, não aparecem no formato de coautorias internacionais em publicações, um dos principais formatos oficiais para contabilização da produção dos pesquisadores nas universidades.

\section{Considerações finais}

O conjunto de elementos apresentados permite delinear casos paradigmáticos que ilustram diferentes modos de conceber, planejar e realizar pesquisas no campo da educação. 
Nesse sentido, o primeiro caso (PE3) representaria o acadêmico que, não obstante apresentar baixa produção bibliográfica relativa à sua área de atuação (capital científico puro) e baixa inserção política em cargos de gestão (capital científico político), possui bolsa de produtividade do CNPq e desfruta, portanto, de prestígio no seu respectivo campo. A hipótese aqui sustentada é que tal prestígio é viabilizado fundamentalmente por meio da experiência. Este primeiro caso é ilustrado por um pesquisador que relata ter viabilizado, com maior facilidade do que em tempos atuais, uma posição de destaque em sua área, haja vista que foi um dos fundadores de um dos primeiros programas de pós-graduação em educação. Sobre o modo de produção do conhecimento, este mesmo pesquisador mantém uma posição que é bastante representativa não apenas no campo da educação, mas na grande área de CHS. Defende que as pesquisas acadêmicas têm a função de formar pesquisadores com rigor, independentemente de publicações que constituam o produtivismo acadêmico. É a atuação no cotidiano da educação escolar, da relação da universidade com a escola, como objeto de investigação e de interação, que importa. Esta atuação é objeto de estudo e nem todo professor universitário deve ou precisa ser pesquisador, na sua ótica. Porém, segundo ele, uma vez que seja pesquisador, o acadêmico precisa ser fiel à sua tarefa de pesquisar e formar novos quadros para a pesquisa, muito mais do que estar preocupado com produtos quantificáveis resultantes dessa tarefa.

O segundo caso (PE1) representaria o pesquisador que consegue realizar uma conciliação entre alta produção bibliográfica (capital científico puro) e alta inserção política em cargos de gestão (capital político). Sobre o modo de produzir conhecimento, neste caso, temos um depoimento que representa uma tendência bastante significativa na pós-graduação. Identificamos aí uma dedicação ao trabalho de campo, com pesquisas que geram intervenção na realidade. Talvez essa posição possa ser identificada com um certo pragmatismo, já que apresenta uma produção relativamente dinâmica de publicações e a necessidade de produzir conhecimento como ferramenta a ser utilizada pela escola e por seus professores, sujeitos das pesquisas, em intervenção social. Podemos sintetizar essa compreensão sobre a pesquisa em educação como um modo de afirmar a vinculação estreita entre a atividade de pesquisa acadêmica e o exercício professoral nas escolas.

O terceiro caso (PE2) representaria o pesquisador que tem uma produção bibliográfica numericamente razoável se considerarmos o conjunto de pares analisado, e apresenta, entretanto, uma inserção política em cargos de gestão. Sobre o modo de produção do conhecimento, neste caso, o pesquisador apresenta a compreensão de que as redes de produção do conhecimento extrapolam as das publicações. Mostra como interage e dialoga com pesquisadores estrangeiros em seminários e congressos que organiza no Brasil, porém sem produzir coautorias a serem registradas no Currículo Lattes. Esse caso expressa uma posição intermediária entre os dois anteriores. Por um lado, não apresenta uma recusa ao jogo da acumulação do capital político nem o coloca como um elemento fundamental de 
investimento. Por outro, em relação à interação entre pesquisa acadêmica e cotidiano escolar, apresenta um posicionamento que não se pauta pela primazia da intervenção e nem pelo distanciamento científico.

Mesmo que formalmente organizados na base de dados do CNPq, os grupos de pesquisa formam-se pelo concurso de interações sociais muitas vezes informais entre pesquisadores. Porém, além destas interações entre membros dos grupos registrados nas plataformas do $\mathrm{CNPq}$ e outros profissionais não formalizados, é interessante ver que a dinâmica das atividades de pesquisa tem origem em múltiplos fatores e trocas sociais não explicitadas. Isso é típico das relações sociais e da capacidade humana de apreender e relacionar objetos e situações aparentemente não vinculados.

O curioso está no fato de que há certas trocas que são de alto valor para a produção de conhecimento na atividade de pesquisa por parte de pesquisadores renomados, e tais trocas não são captadas nos modelos tradicionais de registros individuais de produção científica. Na pesquisa aqui apresentada, não se trata de apontar solução para a questão, mas sim de analisar a complexidade do processo de produção do conhecimento individual e em grupos e redes de colaboração científica, reconhecendo contradições no interior desse processo.

Percebemos que o campo da educação ocupa importante espaço institucional e se organiza com lógicas típicas do campo acadêmico da pesquisa e do campo científico-social ampliado da educação. Conta com pesquisadores destacados que desenvolvem suas atividades de forma heterogênea não só quanto à produção resultante, mas também quanto à forma de conceber redes de pesquisa e objetos de interesses. A distribuição entre o capital científico puro e o capital científico político também expressa essas diferenças, bem como suas ideias sobre redes de pesquisa e colaboração. Porém, a lógica da produção em pesquisa parece aproximar posições no sentido de colocar em questão determinações originadas de estândares externos, como os expressos nos rankings. Esses padrões são fruto das transformações e pressões pelas quais passa a educação superior, modificando os modos de organizar e produzir conhecimento em educação.

Para além das ideias de ciência pura ou ciência servil, o mundo social que se constitui a partir da noção de campo científico permite ver que as disciplinas são capazes de responder de forma variável a pressões externas, de acordo com a maior ou menor clareza na delimitação de sua natureza, de sua atuação e de suas relações com outras disciplinas e campos do conhecimento. A educação como campo, a julgar pelos casos estudados, enfrenta dificuldades para se reconhecer nas transformações atuais do campo científico em geral.

Em acordo com as observações de Bourdieu (2004), quanto maior a legitimidade de um campo na esfera acadêmica e na sociedade, tanto mais consegue obter homogeneidade interna. Ao mesmo tempo, quanto mais bem definida ou até 
hermética for a linguagem que os agentes do campo usam entre si e quanto melhor articulado internamente for um campo, mais força terão no sentido de deter um capital que lhes garanta prestígio na academia e na sociedade. O perigo reside em que um campo de estudos pouco delimitado, como o da educação, transforme-se, mudando de direção para atender a lógicas que talvez não sejam exatamente aquelas que melhor servem aos seus propósitos de estudo dos fenômenos humanos do ensinar e do aprender em sua complexidade e diversidade.

\section{Referências}

BALL, Stephen. Performatividades e fabricações na economia educacional: rumo a uma sociedade performativa. Educação \& Realidade, Porto Alegre, v. 35, n. 2, p. 37-55, maio-ago. 2010.

. Performativity, commodification and commitment: an I-spy guide to the neoliberal university. British Journal of Educational Studies, London, v. 60, n. 1, p. 17-28, Mar. 2012.

BIANCHETTI, Lucídio; MACHADO, Ana Maria Netto. Publicar \& morrer? Análise do impacto das políticas de pesquisa e pós-graduação na constituição do tempo de trabalho dos investigadores. Educação, Sociedade \& Culturas, n. 28, p. 53-69, 2009.

BOURDIEU, Pierre. O campo científico. In: ORTIZ, Renato (Org.). Pierre Bourdieu. São Paulo: Ática, 1983. p. 122-155.

. O poder simbólico. Rio de Janeiro: Difel, 1989.

. Os usos sociais da ciência: por uma sociologia clínica do campo científico. São paulo: Unesp, 2004.

CATANI, Afrânio Mendes. As possibilidades analíticas da noção de campo social. Educação e Sociedade, Campinas, v. 32, n. 114, p. 189-202, jan.-mar. 2011.

CHARLOT, Bernard. A pesquisa educacional entre conhecimentos, políticas e práticas: especificidades e desafios de uma área de saber. Revista Brasileira de Educação, Rio de Janeiro, v. 11, n. 31, p. 7-18, jan.-abr. 2006.

FIORIN, José Luiz. Internacionalização da produção científica. Revista Brasileira da Pós-Graduação, Brasília, v. 4, n. 8, p. 263-281, dez. 2007.

FLICK, Uwe. Desenho da pesquisa qualitativa. Porto Alegre: ArtMed/Bookman, 2009. 
GATTI, Bernadete. Implicações e perspectivas da pesquisa educacional no Brasil Contemporâneo. Cadernos de Pesquisa, São Paulo, n. 113, p. 65-81, 2001.

GIBBONS, Michael et al. La nueva producción del conocimiento: la dinámica de la ciencia y la investigación en las sociedades contemporáneas. Barcelona: Ediciones Pomares-Corredor, 1997.

GRAWITZ, Madeleine. Méthodes des sciences sociales. Paris: Dalloz, 1986.

LAVILLE, Christian; DIONNE, Jean. A construção do saber: manual de metodologia da pesquisa em ciências humanas. Porto Alegre: Artes Médicas, 1999.

LEITE, Denise. Identidades da universidade brasileira. In: LEITE, Denise; BRAGA, Ana Maria Souza (Orgs.). Inovação e avaliação na universidade. Porto Alegre: Editora da UFRGS, 2011. p. 17-40.

LEITE, Denise; GENRO, Maria EllyHerz. Avaliação e internacionalização da educação superior: quo vadis América Latina? Avaliação, v. 17, n. 3, p. 763-785, nov. 2012.

LEITE, Denise; LIMA, Elizeth Gonzaga dos Santos (Orgs.). Conhecimento, avaliação e redes de colaboração: produção e produtividade na universidade. Porto Alegre: Editora Sulina, 2012.

LUDKE, Menga; ANDRÉ, Marli. Pesquisa em educação: abordagens qualitativas. São Paulo: EPU, 2008.

MACHADO, Ana Maria Netto; BIANCHETTI, Lucídio. (Des)fetichização do produtivismo acadêmico: desafios para o trabalhador-pesquisador. RAE, São Paulo, v. 51, n. 3, p. 244-254, maio-jun. 2011.

MERTON, Robert King. La sociología de la ciencia: investigaciones teóricas y empíricas. 2. ed. Madrid: Aliança Editorial, 1985.

MIORANDO, Bernardo Sfredo; LEITE, Denise. Mapeamento de redes de colaboração: detectando inovação e mudanças nas teias de conhecimento. In: LEITE, Denise; LIMA, Elizeth Gonzaga dos Santos (Orgs.). Conhecimento, avaliação e redes de colaboração: produção e produtividade na universidade. Porto Alegre: Editora Sulina, 2012. p. 181-200.

SANTIAGO, Rui; CARVALHO, Teresa; FERREIRA, Andreia. As universidades portuguesas na senda da investigação empreendedora: onde estão as diferenças? Análise Social, Lisboa, v. 48, n. 208, p. 594-620, jul.-set. 2013.

STOER, Stephen Ronald; MAGALHÃES, António. A diferença somos nós: a gestão da mudança social e as políticas educativas e sociais. Porto: Edições Afrontamento, 
Recebido em agosto de 2015.

Aprovado em novembro de 2015.

Célia Elizabete Caregnato é doutora em Educação pela Universidade Federal do Rio Grande do Sul (UFRGS) e professora na UFRGS e atua no Programa de PósGraduação em Educação da mesma universidade. Pesquisa temas sociológicos relacionados à universidade, à educação superior e ao ensino de sociologia.

E-mail: <celia.caregnato@gmail.com>.

Denise Balarine Cavalheiro Leite é doutora em Educação pela Universidade Federal do Rio Grande do Sul (UFRGS) e professora no Programa de PósGraduação em Educação da URGS e tem pesquisas sobre Inovação, Avaliação Institucional, Avaliação Participativa, Avaliação de Redes de Colaboração e Pesquisa, e Pedagogia Universitária. E-mail: <denise.leite@hotmail.com.br>.

Bernardo Sfredo Miorando é doutorando no Programa de Pós-Graduação em Educação da Universidade Federal do Rio Grande do Sul (UFRGS), atuando na linha de pesquisa Universidade: Teoria e Prática. E-mail: <bernardo.sfredo@ufrgs. br>. 